\title{
Preparation and Antibacterial Activity of Silver Nanoparticles
}

\author{
Ratan Das ${ }^{1}$, Sneha Gang ${ }^{2}$, Siddhartha Sankar Nath ${ }^{3 *}$ \\ ${ }^{1}$ Department of Physics, Assam University, Silchar, India; ${ }^{2}$ Department of Biotechnology, Assam University, Silchar, India; ${ }^{3}$ Central \\ Instrumentation Center, Assam University, Silchar, India. \\ Email: "snath12@ymail.com
}

Received January $1^{\text {st }}, 2011$; revised June 27 ${ }^{\text {th }}, 2011$; accepted July $28^{\text {th }}, 2011$.

\begin{abstract}
Uniform silver nanoparticles have been prepared through the chemical reduction of silver ions by ethanol in presence of sodium linoleate. TEM micrograph shows a uniform distribution of the particles with an average size of $12 \mathrm{~nm}$. Further, the antimicrobial activity of silver nanoparticles shows that these nanoparticles can be used as effective growth inhibitors against Staphylococcus Basillus, Staphylloccoccus Aureus, and Pseudimonas Aureginosa.
\end{abstract}

Keywords: Linoleic Acid, Absorption Band, Colloid, Antimicrobial, Microorganisms

\section{Introduction}

Noble metal nanoparticles show unique electronic, optical, magnetic and chemical properties, which differ considerably from those of the corresponding bulk materials [1-3] and hence preparations of noble metal nanoparticles are of technological importance. Recently inorganic nanoparticles protected by organic ligands have attracted much interest due to their diverse technological applications [4-6]. In the present investigation, silver nanoparticles have been synthesized through the chemical reduction of silver ions by ethanol using linoleic acid as a capping agent, which is then dispersed in chloroform to form homogeneous colloidal solution [7] to study the antimicrobial activity of fatty acid (linoleic acid) capped silver nanoparticles. The important advantage is that the silver nanoparticles prepared by this simple reduction process remain stable for one month without any agglomeration. The prepared silver nanoparticles have been examined using Transmission Electron Microscope (TEM) and Fourier Transform Infrared Spectroscopy (FTIR). These studies reveal that average size of freshly prepared silver nanoparticles is $12 \mathrm{~nm}$ with a narrow size distribution.

\section{Materials and Methods}

Uniform silver nanoparticles can be obtained through the reduction of silver ions by ethanol at a temperature of $90^{\circ} \mathrm{C}$ under atmospheric conditions in presence of linoleic acid and sodium linoleate [7]. In this reduction method, $20 \mathrm{ml}$ of aqueous solution containing silver ni- trate $\left(0.6 \mathrm{~g}\right.$ of $\left.\mathrm{AgNO}_{3}\right), 2 \mathrm{~g}$ sodium linoleate $\left(\mathrm{C}_{18} \mathrm{H}_{32} \mathrm{ONa}\right)$, $12 \mathrm{ml}$ ethanol $\left(\mathrm{C}_{2} \mathrm{H}_{5} \mathrm{OH}\right)$ and $2.5 \mathrm{ml}$ linoleic acid $\left(\mathrm{C}_{18}\right.$ $\mathrm{H}_{32} \mathrm{O}_{2}$ ) are added in a capped tube under continuous agitation. The system is kept at the temperatures $90^{\circ} \mathrm{C}$ for 2 hours. In the aqueous solution of silver nitrate, sodium linoleate and the mixture of linoleic acid and ethanol are added in order. Ethanol in the solution phases reduced silver ions into silver nanoparticles. The linoleic acid caps the silver nanoparticles along with the reduction process thereby stabilizes the nanoparticles. In this simple reduction process, the role of linoleic acid is to protect the silver nanoparticles from aggolomeration, by making a layer over them with its alkyl chains on the outside giving a hydrophilic surroundings to the nanoparticles and hence the produced nanoparticles gain hydrophobic surfaces [7]. In this way, capping these particle linoleic acid stabilise them for one month. The product, collected at the bottom of vessel after cooling to room temperature, is dispersed in chloroform to form a homogenous colloidal solution of silver nanoparticles, which is reddish brown in colour as shown in Figure 1(a) with the structure of linoleic acid as shown in Figure 1(b).

\section{Results}

\subsection{TEM Image Analysis}

Size and shape of the silver nanoparticles have been obtained from TEM micrograph, which was performed on a JEM 1000C X II model instrument. TEM micrograph of the prepared colloidal solution of silver nanoparticles is shown in the Figure 2(a), which indicates that the size 

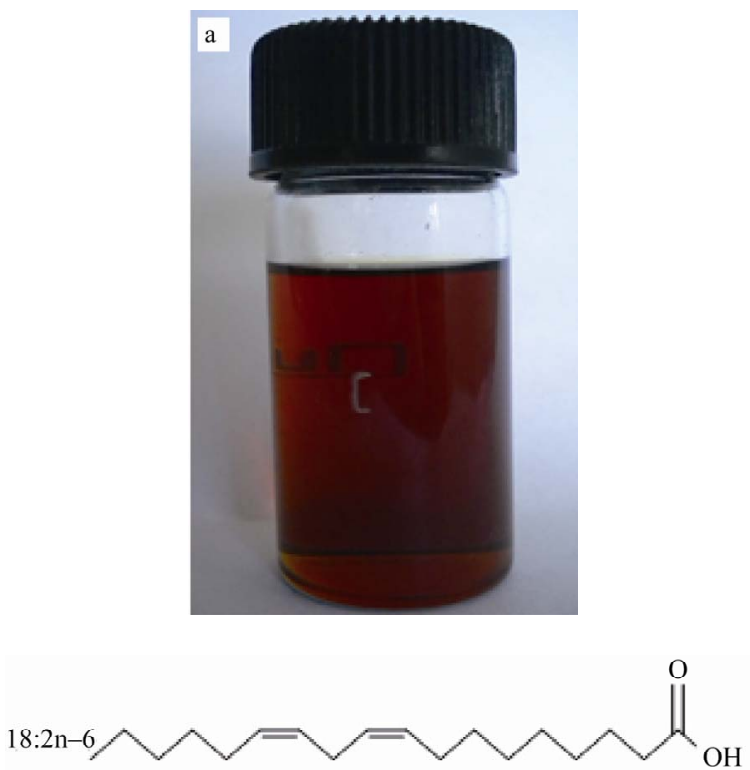

(b) Linoleic Acid

Figure 1. (a) Silver nanoparticles dispersed in chloroform showing reddish brown colour; (b) chemical structure of linoleic acid.

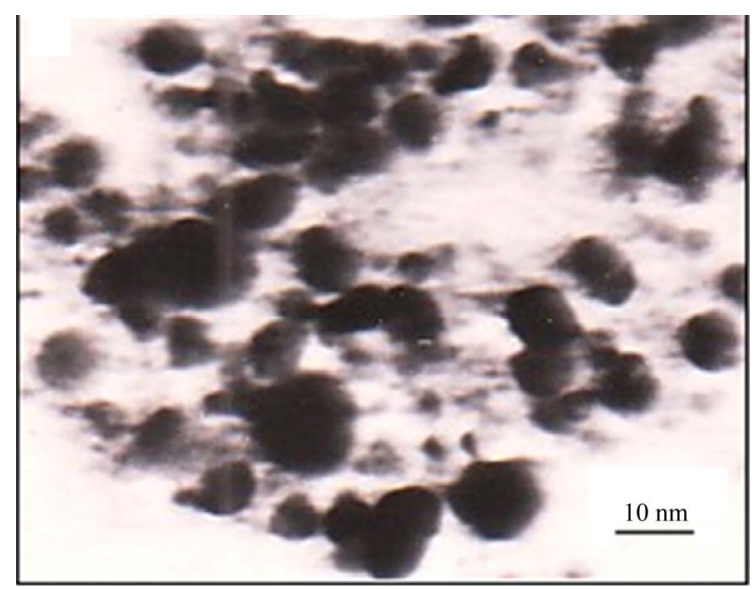

(a)

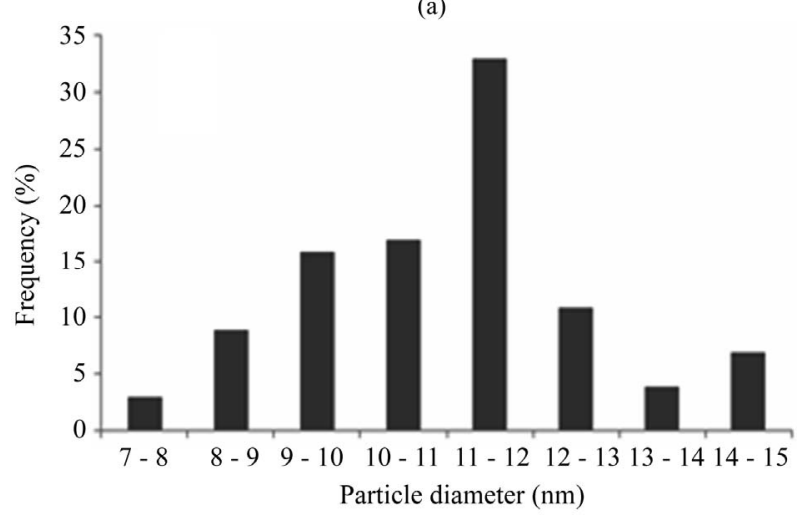

(b)

Figure 2. (a) TEM image of silver nanoparticles; (b) particle size distribution. distribution of silver nanoparticles is narrow as shown in Figure 2 (b), having an average diameter (size) of $12 \mathrm{~nm}$ with the size range $7-15 \mathrm{~nm}$. This TEM image suggests that no clustering of nanoparticles takes place as they are well separated from each other.

\subsection{FTIR Spectroscopy Analysis}

Capping of linoleic acid on silver nanoparticle has been examined by FTIR spectroscopy. The FT-IR absorption spectra of the samples are shown in Figure 3 with resolution of $4 \mathrm{~cm}^{-1}$, which was performed in Spectrum BX series. The peak at $3441 \mathrm{~cm}^{-1}$ of the FTIR spectra contains $\mathrm{OH}$ stretching modes [8]. The peak around 3018 $\mathrm{cm}^{-1}$ is due to $\mathrm{C}=\mathrm{C}$ stretching mode. The lack of broad peak due to $\mathrm{OH}$ stretching of the free ligand in the range $3000 \mathrm{~cm}^{-1}$ to $3100 \mathrm{~cm}^{-1}$ is due to the chemisorptions of linoleic acid on the silver nanoparticles, which is an indicator for the conformational ordering of the metallinked alkyl chains of linoleic acid.

\subsection{Antimicrobial Activity of Silver Nanoparticles}

The antimicrobial effects of silver salts have been noticed since ancient times [9]. But with the advent of nanotechnology, the use of silver in nanoparticle form has opened new treatment avenues. Here antimicrobial activity of this linoleic acid capped silver nanoparticles have been investigated against Staphylococcus Basillus, Staphylloccoccus Aureus, and Pseudimonas Aureginosa by the Kirby-Bauer diffusion method [10,11]. The bacterial suspension was applied uniformly on the surface of a Muller Hinton agar (MHA) plate at a concentration of $10^{5}$ to $10^{6} \mathrm{CFU} / \mathrm{mL}$ before placing antibiotic impregnated disks (Kanamycin and Arithromycin) and silver nanoparticles laden disk (5 mm diameter). For antibacte-

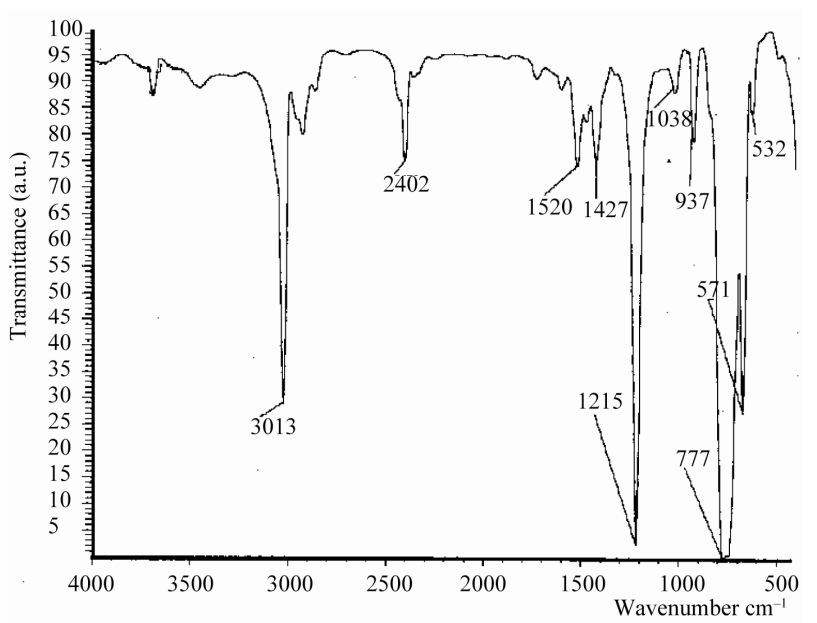

Figure 3. FT-IR spectra of linoleic acid protected silver nanoparticles dispersed in chloroform. 
rial study silver nanoparticles laden disk have been prepared by keeping 10 disks in $5 \mathrm{ml}$ colloidal solution of silver nanoparticles for two days. These disks absorb the silver nanoparticles and become dry and hence there is no presence of chloroform. So there is no impact of solvent to the bacteria. The plates with the discs were incubated at $35^{\circ} \mathrm{C}$ for $24 \mathrm{~h}$, after which the average diameter of the inhibition zone surrounding the disk was measured with a ruler. Figure 4 shows plates to which Staphylococcus Basillus and Staphylloccoccus Aureus bacterial suspension were applied with nanoparticles laden disk and antibiotic impregnated disks. The diameter of inhibition zones around the disk containing silver nanoparticles in S. Basillus, S. Aureus, and Pseudimonas Aureginosa bacterial suspension are $9 \mathrm{~mm}, 11 \mathrm{~mm}, 10 \mathrm{~mm}$ respectively. This test shows that silver nanoparticles are nearly $70 \%, 85 \%$ and $60 \%$ effective compare to Kanamycin and Arithromycin respectively. It is observed that the presence of silver nanoparticles inhibited bacterial growth by more than $97 \%$.

The mechanism of the bactericidal effect of silver nanoparticles is not very well-known. It is believed that cellular proteins become inactive after treatment with silver nanoparticles [12]. It is also believed that silver nanoparticles after penetration into the bacteria have inactivated their enzymes, generating hydrogen peroxide and caused bacterial cell death [11]. Heavy metals are toxic and react with proteins, therefore they bind protein molecules; as a result cellular metabolism is inhibited causing death of microorganism [12]. It is known that silver sources such as silver nitrate and silver sulfadiazine release $\mathrm{Ag}^{+}$only [12] but high activity of silver nanoparticles is attributed to the release of $\mathrm{Ag}^{0}$ and $\mathrm{Ag}^{+}$ clusters when they dissolve [12]. Our experimental result shows that linoleic acid capped silver nanoparticles can be used as effective growth inhibitors in various micro-

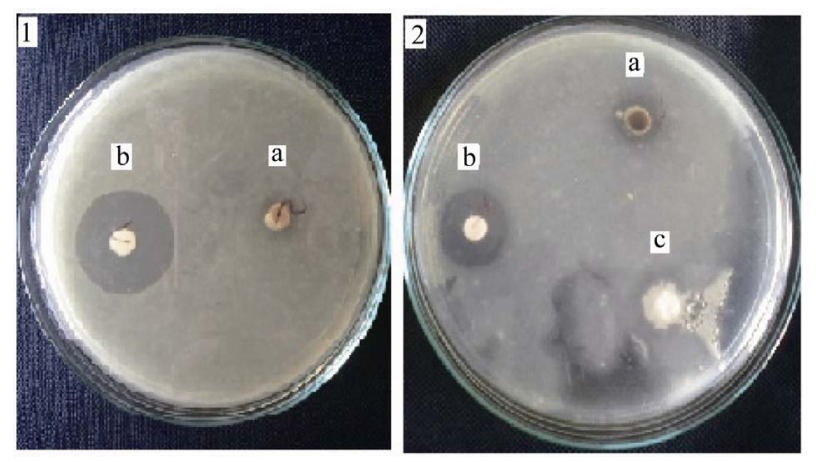

Figure 4. Shows silver nanoparticles laden disk (a) and antibiotic impregnated disk (b, c) placed on the surface of the Staphylococcus Basillus(1) and Staphylloccoccus Aureus(2) bacterial suspension on Muller Hinton agar (MHA) plate after incubation at $35^{\circ} \mathrm{C}$ for $24 \mathrm{~h}$. organisms, making them applicable to diverse medical medicines and antimicrobial control systems.

\section{Discussion}

Uniform linoleic acid capped silver nanoparticles have been prepared through the reduction of silver ions by ethanol. TEM micrograph reveals that the prepared nanoparticles are spherical in shape with average size of 12 $\mathrm{nm}$ having nearly uniform distribution and FTIR spectra confirms the capping of linoleic acid on nanoparticles surfaces. These linoleic acid capped silver nanoparticles are tested for its antimicrobial activity and the result shows that silver nanoparticles can be used as effective growth inhibitors in various microorganisms thereby applicable to diverse medical devices.

\section{Acknowledgements}

Authors thanks to Dr B. Dkhar (S.O.), NEHU, Shillong, India, Dr. A. K. Paul, NEHU, Shillong, India, and Prof. Arun Chottapadhay, IIT, Guwahati, Assam, India for their suggestions and assistance during the work.

\section{REFERENCES}

[1] D. L. Feldheim and C. A. Foss, "Metal nanoparticles: Synthesis, Characterization and Applications,” Marcel Dekker Inc., New York, 2002.

[2] G. Cao, "Nanostructures and Nanomaterials," Edited by Imperial College Press, London, 2004.

[3] C. P. Poole and F. J. Owens, "Introduction to Nanotechnology,” Edited by Wiley Interscience Publication, New Jersey, 2005.

[4] M. Brust, M. Walker, D. Bethell, D. J. Schiffrin and R. J. Whyman, "Synthesis of Thiol Derivatised Gold Nanoparticles in a Two Phase Liquid/Liquid System," Journal of the Chemical Society, Chemical Communications, Vol. 7, No. 7, 1994, pp. 801-802. doi:10.1039/c39940000801

[5] A. S. Nair and T. Y. Pradeep, "Halocarbon Mineralization and Catalytic Destruction by Metal Nanoparticles," Current Science, Vol. 84, No. 12, 2003, pp. 1560-1564.

[6] Y. Fang, "Optical Absorption of Nanoscale Colloidal Silver: Aggregate Band and Adsorbate-Silver Surface Band,” Journal of Physical Chemistry, Vol. 108, No. 10, 1998, pp. 4315-4318. doi:10.1063/1.475831

[7] X. Wang, J. Zhuang, Q. Peng and Y. Li, “A General Strategy for Nanocrystal Synthesis,” Nature, Vol. 437, No. 7055, 2005, pp. 121-124. doi:10.1038/nature03968

[8] M. D. Porter, T. B. Bright, D. L. Allara, and C. E. D. Chidsey, "Chemical Functionality in Self-Assembled Monolayers and Electrochemistry," Journal of the American Chemical Society, Vol. 109, No. 12, 1987, pp. 3559- 3568. doi:10.1021/ja00246a011

[9] M. Bahadory, "Synthesis of Noble Metal Nanoparticles," Dissertation, Drexel University, Philadelphia, 2008.

[10] S. Pal, Y. Kyung and J. M. Song, "Does the Antibacterial 
Activity of Silver Nanoparticles Depend on the Shape of the Nanoparticle? A Study of the Gram-Negative Bacterium Escherichia coli," Applied and Environmental Microbiology, Vol. 73, No. 6, 2007, pp. 1712-1720. doi:10.1128/AEM.02218-06

[11] M. Raffi, F. Hussain, T. M. Bhatti, J. I. Akhter, A. Hameed and M. M. Hasan, "Antibacterial Characterization of Silver Nanoparticles against E. coli ATCC-15224,” Journal of
Materials Science and Technology, Vol. 24, No. 2, 2008, pp. 192-196.

[12] M. Kokkoris, C. C. Trapalis, S. Kossionides, R. Vlastou, B. Nsouli, R. Grotzschel, S. Spartalis, G. Kordas and T. Paradellis, "RBS and HIRBS studies of nanostructured $\mathrm{AgSiO}_{2}$ Sol-Gel Thin Coatings," Nuclear Instruments and Methods B, Vol. 188, No. 1-4, 2002, pp. 67-72. doi:10.1016/S0168-583X(01)01020-5 